\title{
Lead Remediation of Contaminated Water by Charcoal, LA Red Clay, Spinach, and Mustard Green
}

\author{
Lovell Agwaramgbo*, Eucharia Agwaramgbo, Chanel Mercadel, Shelby Edwards, Eric Buckles
}

Chemistry Department, Dillard University, New Orleans, USA.

Email: *lagwaramgbo@dillard.edu

Received August 29 $9^{\text {th }}$ 2011; revised October $3^{\text {rd }}$, 2011; accepted November $4^{\text {th }}, 2011$.

\begin{abstract}
Lead is a toxic and naturally occurring substance with documented neurotoxin, toxic, and long-lasting adverse health effects globally. Lead exposure can cause impaired physical and mental development in children. Exposure to high lead levels affects the intestinal tract, kidneys, joints and reproductive system in adults. This study evaluates the removal of 1500 PPM of lead from contaminated aqueous solution using Celite, Louisiana Red Clay, Charcoal, and supernatants from aqueous extracts of Mustard Green (Brassica juncea), and Spinach (Spinacea oleracea). After shaking triplicate reaction mixtures for each substrate for 22 hours at room temperature, lead removal by the five substrates were analyzed by EPA Method 6010, using Inductively Coupled Plasma-Atomic Emission Spectrometry (ICP-AES). Results suggest that the order of lead removal is Spinach (98\%) > Charcoal (96\%) > LA Red Clay (88\%) > Mustard Green (87\%) $>$ Celite (4\%). The study concludes that liquid substrates such as the supernatants from pureed spinach and mustard green can effectively remove lead from contaminated water.
\end{abstract}

Keywords: Remediation, Heavy Metal, Lead, Water Contamination, Spinach, Contaminated Water

\section{Introduction}

Water and soil lead contamination poses serious human health risks with global dimensions [1-3]. Lead does not undergo degradation or decomposition. Thus, its long persistence in the environment exacerbates its threat to human health. It is estimated to persist in the soil for 5000 years [4]. Historical lead pollution results from a variety of human activities such as past practices of leadrelated industrial processes, smelting, chipping of old lead paint, disturbance of old paint during renovation, combustion of coal [5-8], mining activities [9], use of lead based paints and automotive exhaust fumes [10-12], manufacture and use of agricultural fertilizers, insecticides, and pesticides [13].

Disasters such as hurricane Katrina exacerbate the redistribution of lead in the environment $[14,15]$. Ingestion of lead contaminated soil, water, and food and inhalation of lead dust [11,12] are important and serious routes of lead exposure and entry into the human body. Various adverse health effects of high lead exposure have been reported in children; particularly, impaired mental development, reduced cognitive ability, learning difficulties, and low IQ [11,12,16-19], low quantitative skills [20], and neurotoxicity [21]. Lead exposure to adults has health consequences such as cognitive dysfunction from early childhood exposure [22], diabetes, damage to the male and female reproductive systems, and renal disease [23].

Recent studies suggest that neurological damage from early childhood exposure to lead contributes to delinquent and criminal behaviors [24,25].

Each of the existing technologies for lead remediation (capping, subsurface barriers, in-situ/ex-situ solidification/stabilization, and chemical and biological treatment) has its own inherent drawbacks or limitations in terms of cost, long term effectiveness, general acceptance, applicability at higher lead concentration, type of contaminants, and reduction in toxicity, mobility, and volume [26]. Phytoremediation, a vegetative environmentally friendly and nascent green technology is proving to be very cost effective and a safe method to remediate a variety of pollutants. However, it also has its own limitations [27]: 1) limitation of root zone depth 2) phytotoxicity at high contaminant levels and 3) rate of contaminant uptake by 
plant.

Although new methods for removing lead from water are beginning to emerge, yet many of them have their shortcomings [28-31], they either introduce chemical to the water or affect the $\mathrm{pH}$ or salinity of the water. Therefore, this project examines phytoremediation option that does not use live-plant but uses supernatant extract of spinach and mustard green.

\section{Materials \& Methods}

\subsection{Preparation of Lead Nitrate Solution 1500 Parts per Million (PPM)}

Using an analytical balance, $1.5 \mathrm{~g}$ of lead Nitrate from Fisher Scientific (L6200) was dissolved in enough deionized water (added incrementally) to give $1000 \mathrm{ml}$ of solution. Then a stirring bar was dropped into the volumetric flask and the mixture was stirred until all the lead was completely dissolved. The flask was wrapped with aluminum foil to avoid much exposure to light while the solution continued to stir at room temperature until it was used.

\subsection{Preparation of 750 PPM of Lead Nitrate Solution}

To $25 \mathrm{ml}$ of the 1500 PPM lead nitrate solution prepared above was added $25 \mathrm{ml}$ of deionized water. This will represent a control for the dilution that will occur when 25 $\mathrm{ml}$ of spinach and mustard green supernatants are added to $25 \mathrm{ml}$ of the 1500 PPM lead solution, respectively. The resulting solution was vortexed using a Genie 2 vortex and stirred to mix.

\subsection{Preparation of Spinach Supernatant}

Fresh spinach (100 grams) bought from a local market was washed with deionized water and patted dry with kimwipes. The $100 \mathrm{~g}$ of spinach was pureed in a regular kitchen blender using $200 \mathrm{ml}$ of de-ionized water. The puree was filtered using a white handkerchief bought from a local Wal-Mart store. The filtrate was put into four-50 ml centrifuge tubes and centrifuged at $3000 \mathrm{rpm}$ for 10 minutes using a Thermo Centra CL2 bench-top centrifuge. Using a pipette, three- $25 \mathrm{ml}$ portions of the resulting supernatant was carefully transferred into three$50 \mathrm{ml}$ centrifuge tubes, respectively. The tubes were capped, labeled, and put in the refrigerator for later use within one hour.

\subsection{Preparation of Mustard Green Supernatant}

Following the procedure used for the Spinach, the Mustard Green was pureed, filtered and centrifuged. The resulting supernatant was transferred into three- $50 \mathrm{ml}$ centrifuge tubes in $25 \mathrm{ml}$ portions, respectively. The tubes were capped, labeled, and put in the refrigerator for later use within one hour.

\subsection{Preparation for Charcoal, LA Red Clay, \& Celite Reaction with Lead Solution}

\subsubsection{Preparation for Charcoal Reaction}

Three 50-ml centrifuge tubes were charged with $4 \mathrm{~g}$ of charcoal (activated carbon, Norit, RO 0.8 pellets) purchased from Aldrich Chemical Company, cat \# 329428). The centrifuge tubes were capped and labeled.

\subsubsection{Preparation for LA Red Clay Reaction}

Three $50 \mathrm{ml}$ centrifuge tubes were charged with $4 \mathrm{~g}$ of Louisiana Red Clay soil (composed of $10.6 \%$ sand, $36.5 \%$ silt, and $52.9 \%$ clay), respectively. The centrifuge tubes were capped and labeled.

\subsubsection{Preparation for Celite Reaction}

Three $50-\mathrm{ml}$ centrifuge tubes were charged with $4 \mathrm{~g}$ of activated charcoal (bought from Aldrich Chemical). The centrifuge tubes were capped and labeled.

\section{Reaction of the Supernatants, Celite, LA Red Clay, and Charcoal}

\subsection{Reaction of Lead Solution with Spinach and Mustard Green Supernatants}

Into each centrifuge tube containing $25 \mathrm{ml}$ of the spinach and mustard green supernatants was added $25 \mathrm{ml}$ of the lead nitrate solution (1500 PPM) prepared above. The six tubes and their contents were vortexed, tightly secured on the rack of a heavy duty Eberbach 6000 shaker, and agitated for 22 hours at room temperature.

\subsection{Reaction of Lead Solution with Celite, Charcoal, and Louisiana Red Clay}

Forty milliliters (40 ml) of lead solution (1500 PPM) was added to each of the triplicate centrifuge tubes for the three solid substrates (Charcoal, Louisiana Red Clay, and Celite). The tubes and their contents were vortexed, tightly secured on a rack of a heavy duty Eberbach 6000 shaker, and agitated for 22 hours at room temperature.

\section{Sample Preparation and Analysis}

\subsection{Sample Preparation}

After $22 \mathrm{hrs}$, the shaker was stopped and the tubes were centrifuged at $3000 \mathrm{rpm}$ for ten minutes. The resulting clear supernatant in each tube was transferred into another labeled clean centrifuge tube. All the labeled centrifuge tubes with their liquid contents were sent to PACE Analytical Services, Inc for lead analysis using EPA method 6010. Note that PACE Analytical Services, Inc is a commercial environmental laboratory that is accredited in accordance to the National Environmental Laboratory Accreditation Conference (NELAC). 


\subsection{Sample Analysis for Lead after Reaction}

After the reaction period, the lead concentration (in PPM) in the liquid from each reaction tube was analyzed using EPA Method 6010 (Inductively Coupled Plasma-Atomic Emission Spectrometry (ICP-AES)).

\section{Results}

Table 1 shows the amount of lead in PPM remaining in each reaction tube after 22 hrs: Control (1503); Celite (1446); LA Red Clay (185); Mustard Green (98); Charcoal (68); and Spinach (13). Table 1 also shows the average percent of lead removed by each substrate: Celite (4\%), Mustard green (87\%), LA Red Clay (88\%), Charcoal (96\%), and Spinach (98\%). Figure 1 illustrates the varying ability of various substrates to remove lead from aqueous lead solution in their reactions after twenty two hours at room temperature.

\section{Discussions}

Figure 1 represents the data on the concentration of lead remaining after the contaminated water was treated with each substrate (see Table 1) relative to the control solution. In contrast, Figure 2 compares the percent of lead removed from the contaminated water by each substrate. The results showed that all the substrates except celite removed more than $80 \%$ of lead from the aqueous lead solution as clearly shown in Table 1 and Figure 1). The data further showed the varying abilities of the five substrates to remove lead from contaminated aqueous lead solution.

Thus, the order of lead removal is Spinach (98\%) > Charcoal $(96 \%)>$ LA red clay $(88 \%)>$ mustard green $(87 \%)>>>$ Celite $(4 \%)$ as shown in Figure 2 . The percent of lead removed by the spinach and mustard green supernatants is based on the initial lead concentration assumed to be 752 PPM. This assumption is based on a two fold dilution that potentially occurred when $25 \mathrm{ml}$ of the 1,503 PPM of the aqueous lead solution were mixed with $25 \mathrm{ml}$ of the spinach or mustard green liquid supernatants. Although we set out to prepare 1,500 PPM of lead stock solution; however, the average ICP result of the control after 22 hrs was 1503 PPM. Thus, using the dilution equation $\left(M_{1} V_{1}=M_{2} V_{2}\right)$, where $M_{1}=$ Initial lead concentration; $\mathrm{V}_{1}=$ Initial volume of lead solution, $\mathrm{V}_{2}$ = final volume reaction mixture, and $\mathrm{M}_{2}$, the initial lead concentration when $25 \mathrm{ml}$ of mustard green or spinach each reaction mixture after 22 hrs for spinach was added to $25 \mathrm{ml}$ of aqueous lead solution is calculated to be 751.5 (752) PPM.

It is important to note that a close look at Figure 1, shows that mustard green removed more lead that LA red clay but has a lower calculated percent led removal than
Table 1. Lead left in Reaction Mixtures.

\begin{tabular}{ccc}
\hline Substrates & $\begin{array}{c}{[\mathrm{Pb}] \text { remaining after }} \\
\text { 22 hrs in PPM }\end{array}$ & $\begin{array}{c}\text { \% Lead removal after 22 hrs } \\
\text { by various substrates }\end{array}$ \\
\hline Control & 1503 & 0 \\
Celite & 1446 & 4 \\
LA Red Clay & 185 & 88 \\
Charcoal & 68 & 96 \\
Mustaed Green & 98 & 87 \\
Spinach & 13 & 98 \\
\hline
\end{tabular}

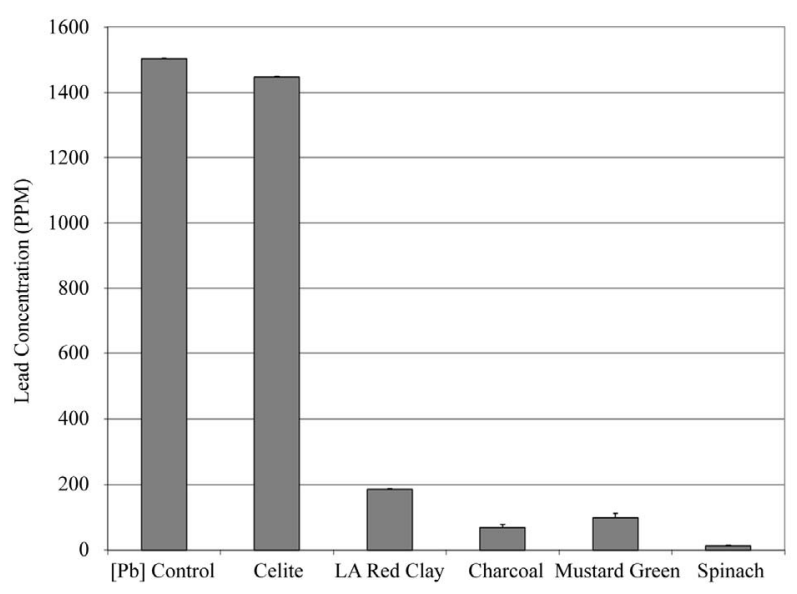

Figure 1. Lead Removal by Substrates Compared to Control.

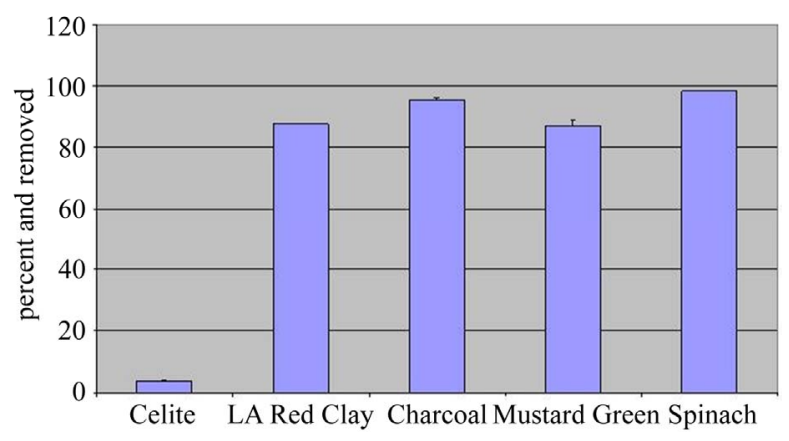

Figure 2. Percent Lead Removed by Substrates.

the value for LA red clay. This is because of the value for the initial lead concentration is taken to be 752 PPM due to dilution effect of the supernatants on lead concentration in the reaction mixture. If the initial lead concentration in the spinach and mustard green reactions is taken to be 1502 PPM, then the percent lead removal by Spinach will be $99 \%$ while that for mustard green will be 93.5\%. For the percent lead removal in reactions of the solid substrates (celite, Louisiana red clay, and charcoal), the initial lead concentration was based on 1503 PPM

\section{Conclusions}

Activated charcoal, Louisiana Red Clay, Mustard Green (Brassica juncea), and extracts of Spinach (Spinacea ol- 
eracea) are found to be efficient in lead removal from contaminated water. Celite did not remove any significant amount of lead from the contaminated water. Although phytoremediation of lead has been reported in the literature with live plants, however, the use of the water extracts of plants for such remediation has not been reported. Taking into account the presented results, the following conclusions are postulated: 1) the research presented here has demonstrated that it may be possible to develop extract-based remediation technology for heavy metals. 2) Although there could be some adsorptive lead removal occurring in the case of clay and activated charcoal reactions, it could not account for all the lead removal considering that celite did not remove significant amount of lead. Thus, the chemical properties of the solid charcoal and red clay may play a critical role in their lead removal ability. 3) Since very limited adsorptive lead removal is expected to occur in the spinach and mustard green extract-reactions, enzymatic or chemical reactions may be involved in their lead removal.

\section{Acknowledgements}

We thank Dr. John Wilson, Atiereya Adley, Adriana Hawkins, Danyelle Wilson, Gulf Coast Fund for Community Renewal and Ecological Health, and Peoples Environmental Center.

\section{REFERENCES}

[1] S. Tong, Y. E. von Schirnding and T. Prapamontol, "Environmental Lead Exposure: A Public Health Problem of Global Dimensions," Bulletin of the World Health Organization, Vol. 78, No. 9, 200, pp. 1068-1077.

[2] U. Forstner, "Land Contamination by Metals: Global Scope and Magnitude of Problem,” In: H. E. Allen, C. P. Huang, G. W. Bailey and A. R. Bowers, Eds., Metal Speciation and Contamination of Soil, CRC Press, Boca Raton, 1995. p.133.

[3] R. M. Brooks, M. Bahadory, F. Tovia and H.n Rostami, "Removal of Lead from Contaminated Water," International Journal of Soil, Sediment, \& Water, Vol. 3, No. 2, 2010, pp. 1-14.

[4] M. S. Laidlaw, H. W. Mielke, G. M. Filippelli, D. L. Johnson and C. R. Gonzales, "Seasonality and Children's Blood Lead Levels: Developing a Predictive Model using Climatic Variables and Blood Lead Data from Indianapolis, Indiana, Syracuse, New York and New Orleans, Louisiana (USA)," Environmental Health Perspectives, Vol. 113, No. 6, 2005, pp. 793-800. doi:10.1289/ehp.7759

[5] A. J. Shaw, "Heavy Metal Tolerance in Plants: Evolutionary Aspects,” CRC Press, Boca Raton, 1990, p. 268.

[6] A. S. Moffat, "Plants Proving Their Worth in toxic metal cleanup,” Science, Vol. 269, 1995, pp. 302-303. doi:10.1126/science.269.5222.302
[7] R. Chaney and H. Mielke, "Standard for Soil Lead limitations in the United States, Trace Substance," Environmental Health, Vol. 20, 1986, p. 358.

[8] T. Sardis, M. K. Chettri, A. Papaioannou, G. Zachariadis and J. Stratis, "A Study of Metal Distribution from fuels, using trees as Biological Monitors,” Ecotoxicology and Environmental Safety, Vol. 48, No. 1, 2001, pp. 27-35. doi:10.1006/eesa.2000.2001

[9] J. Cotter-Howells and I. Thornton, "Sources and Pathways of Environmental Lead to Children in a Derbyshire Mining Village," Environmental Geochemistry and Health, Vol. 13, No. 2, 1991, pp. 127-135. doi:10.1007/BF01734304

[10] M. Weitzman, A. Aschengrau, D. Bellinger and R. Jones, "Lead Contaminated Soil Abatement and Urban Children's Blood Lead Levels," JAMA: The Journal of the American Medical Association, Vol. 269, No. 13, 1993, pp. 1647-1654.

[11] H. W. Mielke, J. L. Adams, P. L. Reagan and P. W. Mielke Jr., "Soil-dust Lead and Childhood Lead Exposure as a Function of City Size and Community Traffic Flow,” The Case for Lead Contaminated Soil Abatement in Minnesota, Environmental Geochemistry and Health, Lead in Soil: Issues and Guidelines, Suppl. 9, 1989, pp. 253-271.

[12] H. W. Mielke, "Lead Dust Contaminated USA Communities, Comparison of Louisiana and Minnesota,” Applied Geochemistry, Vol. 8, Suppl. 2, 1993, pp. 257-261. doi:10.1016/S0883-2927(09)80046-2

[13] Q.Y. Ma, T. J. Logan and S. J. Traina, "Lead Immobilization from Aqueous Solutions and Contaminated Soils Using Phosphate Rocks," Environmental Science \& Technology, Vol. 29, 1995, pp. 1118-1126. doi:10.1021/es00004a034

[14] M. Rotkin-Ellman, G. Solomon, C. R. Gonzales, L. Agwaramgbo and H. W. Mielke, "Arsenic Contamination in New Orleans Soil: Temporal Changes Associated with Flooding," Environmental Research, Vol. 110, No. 1, 2010, pp. 19-25. doi:10.1016/j.envres.2009.09.004

[15] L. Agwaramgbo, J. Smith-Hopkins, A. Hawkins and D. Wilson, "Re-Examination of Lead and Arsenic Contamination in New Orleans Parish School Soils," Chemical and Engineering News, American Chemical Society, CHED-TECH 33, American Chemical Society, Conference, New Orleans, 17 March 2008.

[16] M. A. Smith, “Lead in History,” In: R. Lansdown and W. Yule, Eds., Environmental Toxicology and Child Health, The Lead Debate, London, 1984, pp. 7-24.

[17] G. W. Goldstein, "Neurological Concepts of Lead Poisoning in Children," Pediatric Annals, Vol. 21, No. 6, 1992, pp. 384-388.

[18] S. Tong, "Lead Exposure and Cognitive Development: Persistence and a Dynamic Pattern,” Journal of Pediatrics and Child Health, Vol. 34, No. 2, 1998, pp. 114-118. doi:10.1046/j.1440-1754.1998.00187.x

[19] M. L. Miranda, K. Dohyeong, M. A. Galeano, C. J. Paul, A. P. Hull and S. P. Morgan, "The Relationship between 
Early Childhood Blood Lead Levels and Performance on End-of-Grade Tests,” Environmental Health Perspectives, Vol. 115, No. 8, 2007, pp. 1242-1247.

doi:10.1289/ehp.9994

[20] R. L. Canfield, C. R. Henderson Jr., D. A. Cory-Slechta, C. Cox, T. A. Jusko and B. P. Lanphear, "Intellectual Impairment in Children with Blood Lead Concentrations below $10 \mu \mathrm{g}$ per Deciliter," New England Journal of Medicine, Vol. 348, 16, 2003, pp. 1517-1526. doi:10.1056/NEJMoa022848

[21] H. Needleman, C. McFarland, R. Ness, S. Fienberg and M. Tobin, "Bone Lead Levels in Adjudicated Delinquents: A Case Control Study,” Neurotoxicology and Teratology, Vol. 24, No. 6, 2003, pp. 711-717. doi:10.1016/S0892-0362(02)00269-6

[22] R. A. Shih, H. Hu, M. G. Weisskopf and B. S. Schwartz, "Cumulative Lead Dose and Cognitive Function in Adults: A Review of Studies That Measured Both Blood Lead and Bone Lead," Environmental Health Perspectives, Vol. 115, No. 3, 2007, pp. 483-492. doi:10.1289/ehp.9786

[23] J. L. Lin, D. T. Lin-Tan, K. H. Hsu and C. C. Yu, "Environmental Lead Exposure and Progression of Chronic Renal Diseases in Patients without Diabetes,” New England Journal of Medicine, Vol. 348, 2003, pp. 277-286. doi:10.1056/NEJMoa021672

[24] R. Nevin, "Understanding International Crime Trends: The Legacy of Preschool Lead Exposure,” Environmental Research, Vol. 104, No. 3, 2007, pp. 315-336. doi:10.1016/j.envres.2007.02.008

[25] P. B. Stretesky and M. J. Lynch, “The Relationship be- tween Lead Exposure and Homicide," Archives of Pediatric and Adolescent Medicine, Vol. 155, No. 5, 2001, pp. 579-582.

[26] C. Evanko and D. Dzonbak, "Remediation of Metal Contaminated Soils and Groundwater," Groundwater Remediation Technologies Analysis Report, Series b TE-97-01, 1997, pp. 1-53.

[27] V. Medina, S. L. Larson, L. Agwaramgbo, W. Perez and L. Escalon, "Treatment of Trinitrotoluene by Crude Plant Extracts,” Chemosphere, Vol. 55, No. 5, 2004, pp. 725732. doi:10.1016/j.chemosphere.2003.12.014

[28] A. El Nemr, A. El Sikaily, A. Khaled and O. Abdelwahab, "Removal of Toxic Chromium (VI) from Aqueous Solution by Activated Carbon Using Casuarina Equisetifolia," Chemistry and Ecology, Vol. 23, No. 2, 2007, pp. 119129. doi:10.1080/02757540701197754

[29] S. S. Baral, S. N. Dasa, P. Rath, G. Roy Chaudhury and Y. V. Swamy, "Removal of Cr(VI) from Aqueous Solution Using Waste Weed, Salvinia Cucullata," Chemistry and Ecology, Vol. 23, No. 2, 2007, pp. 105-117. doi:10.1080/02757540701197697

[30] A. W. Rate, "Sorption of Cadmium (II) and Copper (II) by Soil Humic Acids: Temperature Affects and Sorption Heterogeneity," Chemistry and Ecology, Vol. 26, No. 5, 2010, pp. 371-383. doi:10.1080/02757540.2010.504666

[31] L. M. Mataka, E. M. Henry, W. R. L. Masamba and S. M. Sajida, "Lead Remediation of Contaminated Water Using Moringa Stenopetala and Moring Oleifera Seed Powder," International Journal of Environmental Science and Technology, Vol. 3, No. 2, 2006, pp. 131-139. 